\title{
Article \\ Perinatal Outcomes in Premature Placental Calcification and the Association of a Color Doppler Study: Report from a Tertiary Care Hospital in Eastern India
}

\author{
Sudarshan Dash ${ }^{1}$, Banya Das ${ }^{1}$, Soumya Ranjan Panda ${ }^{1, *}$, Monalisa Rajguru ${ }^{1,2}$, Pramila Jena ${ }^{1}$, \\ Abheepsa Mishra ${ }^{3}$ iD and Sudhanshu Kumar Rath ${ }^{1}$ \\ 1 Department of Obstetrics and Gynaecology, Kalinga Institute of Medical Sciences, KIIT University, \\ Bhubaneswar 751024, India; sudarshan.dash@kims.ac.in (S.D.); banyadas.parija23@gmail.com (B.D.); \\ monalisha.rajguru@gmail.com (M.R.); pramila.jena@kims.ac.in (P.J.); sudhanshu.rath@kims.ac.in (S.K.R.) \\ IMO-JB, ESIC Hospital, Bhubaneswar 751022, India \\ 3 The Feinstein Institute for Medical Research, Manhasset, NY 11030, USA; mishra.abheepsa@gmail.com \\ * Correspondence: soumyaranjan.panda@kims.ac.in; Tel.: +91-94603-79740
}

check for updates

Citation: Dash, S.; Das, B.; Panda, S.R.; Rajguru, M.; Jena, P.; Mishra, A.; Rath, S.K. Perinatal Outcomes in Premature Placental Calcification and the Association of a Color Doppler Study: Report from a Tertiary Care Hospital in Eastern India. Clin. Pract. 2021, 11, 841-849. https://doi.org/ 10.3390/clinpract11040099

Academic Editor: Aya Mousa

Received: 2 September 2021

Accepted: 4 November 2021

Published: 9 November 2021

Publisher's Note: MDPI stays neutral with regard to jurisdictional claims in published maps and institutional affiliations.

Copyright: (c) 2021 by the authors. Licensee MDPI, Basel, Switzerland. This article is an open access article distributed under the terms and conditions of the Creative Commons Attribution (CC BY) license (https:/ / creativecommons.org/licenses/by/ $4.0 /)$.
Abstract: Introduction: Placental calcification, identified before the 36th week of gestational age, is known as premature placental calcification (PPC). PPC could be a clue for the poor fetal outcome. However, its association with adverse perinatal outcomes is yet to be confirmed. Objective: The primary objective was to determine and compare the perinatal outcomes in pregnancies with and without documented premature placental calcification. Methodology: The present study was a prospective cohort study performed from October 2017 to September 2019. We consecutively enrolled 494 antenatal women who presented to our antenatal OPD after taking consent to participate in our study. Transabdominal sonographies were conducted between 28-36 weeks of gestation to document placental maturity. We compared maternal and fetal outcomes between those who were identified with grade III placental calcification $(n=140)$ and those without grade III placental calcification $(n=354)$. Results: The incidence of preeclampsia, at least one abnormal Doppler index, obstetrics cholestasis, placental abruption, and FGR (fetal growth restriction) pregnancies were significantly higher in the group premature placental calcification. We also found a significantly increased incidence of Low APGAR (Appearance, Pulse, Grimace, Activity, and Respiration) scores, NICU (Neonatal Intensive Care Unit) Admission, Abnormal CTG (cardiotocography), meconium-stained liquor, and low birth weight babies in those with grade III placental calcification. Conclusion: Clinicians should be aware of documenting placental grading while performing ultrasonography during 28 to 36 weeks. Ultrasonographically, the absence of PPC can define a subcategory of low-risk pregnant populations which probably need no referral to specialized centers and can be managed in these settings.

Keywords: premature placental calcification; perinatal outcome; Doppler ultrasonography

\section{Introduction}

Grade III placental calcification is a physiological aging process often found during term pregnancy [1-3]. It is known as premature placental calcification (PPC) when identified before the onset of the 36th week of gestation. PPC may be a clue for poor fetal outcome. However, the evidence for its association with the adverse feto-maternal outcomes seems ambiguous. Weinsberg and his group [4] first detected placental calcification with fetal maturity, followed by Granumm and his group [5], who first applied grading to the placenta. The prevalence of PPC is ranging from $3.8 \%$ to $23.7 \%$ in various studies [6,7]. Some studies reported the association of PPC with the incidence of FGR (fetal growth restriction), LBW (low birth weight) babies, and poor APGAR (Appearance, Pulse, Grimace, Activity, and Respiration) scores [6,8]. However, other investigators could not find such an association [1-3]. 
The varied results derived from these studies are confusing, which could be due to multiple causes. First, most of these studies were done years ago with ultrasound machines of lower resolution than the modern ones. Secondly, the study population was too small to provide a proper conclusion. Thirdly, cigarette smoking, diabetes, and hypertension were dismissed as confounding factors in a few studies. Hence, the current study aimed to address the grey areas on the feto-maternal outcomes of PPC-associated pregnancies.

\section{Objective}

The primary objective was to determine and compare the perinatal outcomes in pregnancies with and without documented premature placental calcification.

\section{Materials and Methods}

\subsection{Study Design}

The prospective cohort study was performed between October 2017 to September 2019 after taking approval from the Institutional ethical committee of the hospital with EC registration number KIMS/KIIT/IEC/38/2017 dated 13 June 2017. After taking written informed consent, all antenatal women attending our OPD (Outpatient Department) were included in the study. The participants were enrolled $(\mathrm{N}=494)$, and transabdominal sonographies were conducted between 28-36 weeks of gestation to document placental maturity. We compared maternal and fetal outcomes between patients identified with grade III placental calcification $(\mathrm{n}=140)$ and those without grade III placental calcification $(n=354)$. Figure 1 shows the flowchart of the selection of participants for our study.

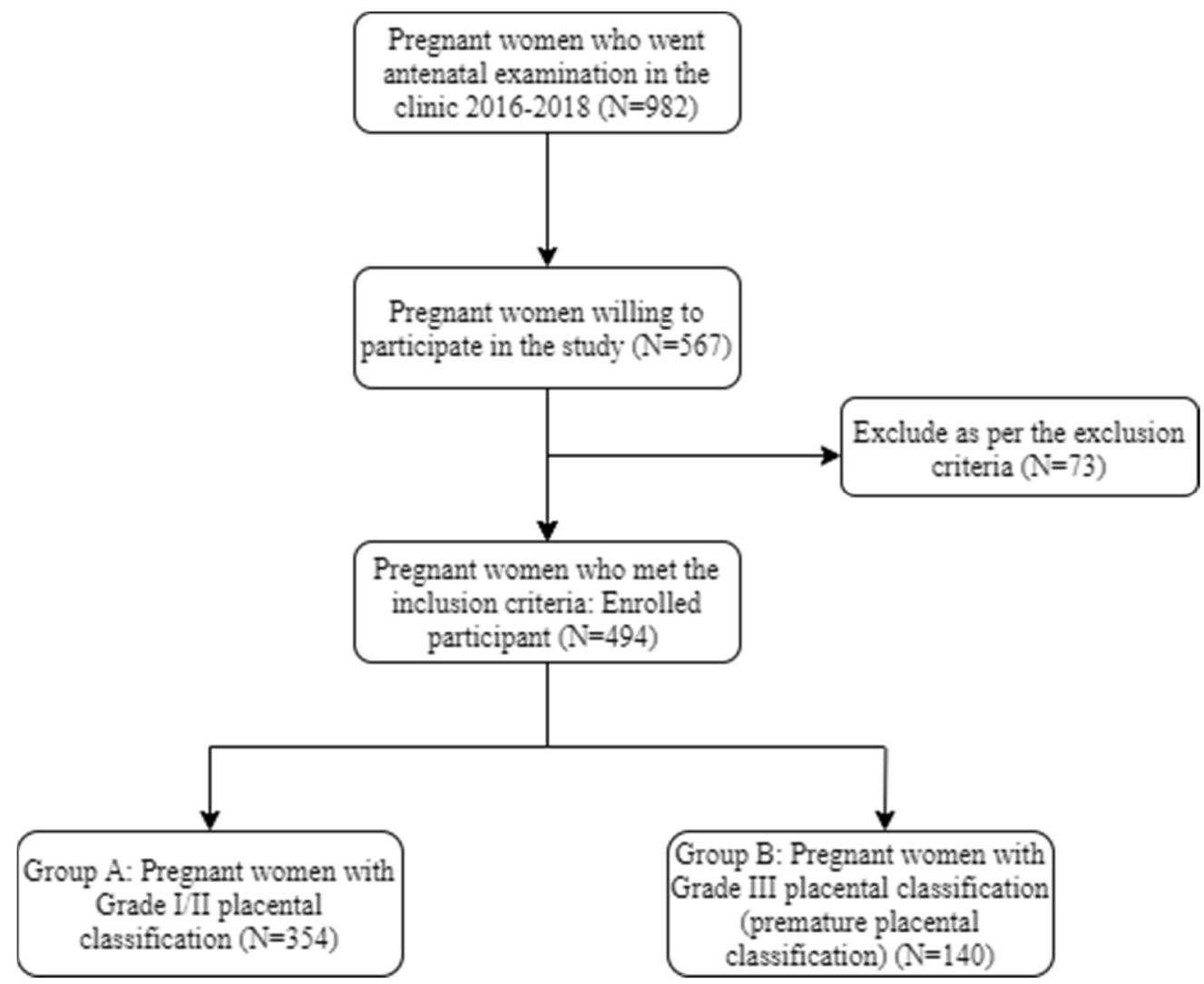

Figure 1. Flowchart showing participant selection criteria.

Ultrasound was performed to document the cases of PPC from 28 weeks of gestation at every four-week interval. Echogenic indentation from the chorionic plate to the basal layer dividing the placenta into random lobules, similar to cotyledons, was considered Grade III placental calcification (Figure 2A,B). A doppler flow study was conducted starting from 32 weeks of gestation to 36 weeks at an interval of 4 weeks. The ultrasound equipment used 
for this study was a Siemens Acuson $\times 300$ PE USG machine with a curvilinear transducer and a frequency of 1.9 to $6.4 \mathrm{MHz}$, analyzed by a single consultant in order to avoid interobserver bias. The images were verified by another senior consultant to ensure the accuracy of diagnosis. Both the consultants were obstetricians trained in ultrasonography. In the umbilical artery Doppler study, absent or reversed end-diastolic velocity (AREDV) was considered to reflect poor uteroplacental blood flow. The other Doppler indices measured were the umbilical artery pulsatility index (Umb PI) $\geq 95$ th, middle cerebral artery pulsatility index (MCA PI $\leq 5$ th), cerebro placental ratio (CPR $\leq 5$ th), Mean uterine $\mathrm{PI} \geq 95$ th, and unilateral or bilateral notch in the uterine artery.

The study participants were divided into two groups based on the presence or absence of premature calcification. Each pregnancy was followed until six weeks postpartum, and in each case, antepartum, intrapartum, and postpartum complications were documented. A comparison was made between two groups for feto-maternal outcome and indices of Doppler velocimetry of the uteroplacental blood flow.

Preeclampsia was defined as raised blood pressure (>140/90 $\mathrm{mm}$ of $\mathrm{Hg}$ ) found between the 20th week of gestation and 6th week of post-partum. Gestational diabetes was defined as carbohydrate intolerance found after the 20th week of gestation as per an oral glucose tolerance test done after the 24 th week of gestation. Placental abruption was suspected clinically if patients developed antepartum hemorrhage after the 28th week of gestation and ultrasonography showing a placenta in its normal location but showing signs of a retroplacental hemorrhage/clot.

Inclusion criteria: All pregnant women attending our antenatal OPD after 28 weeks of gestation were included in this study.

Exclusion criteria: Women with multifetal gestation, congenital anomalies of the fetus, history of smoking and alcohol consumption, previous history of diabetes mellitus, hypertension, and those who did not consent to participate were excluded from the study.

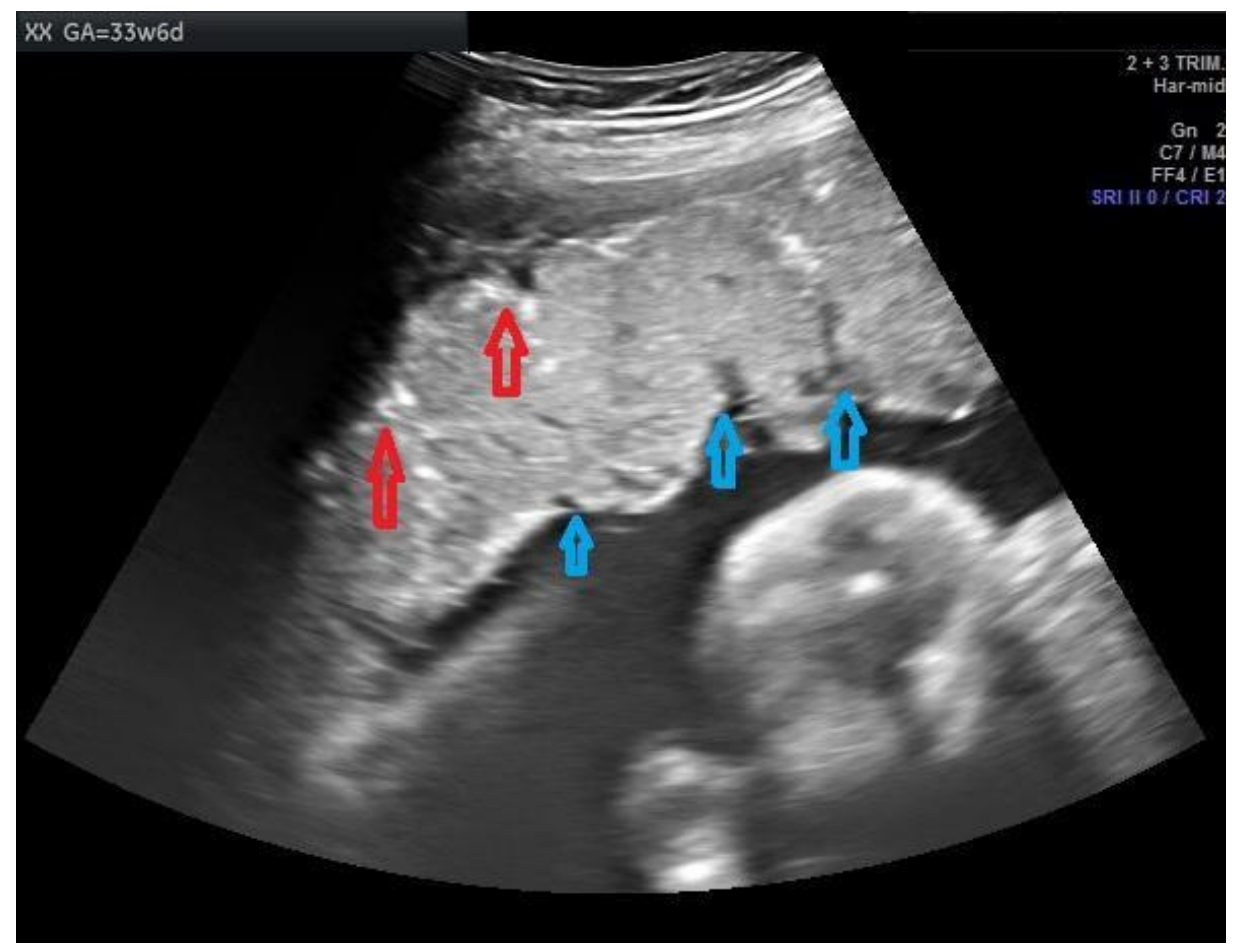

(A)

Figure 2. Cont. 


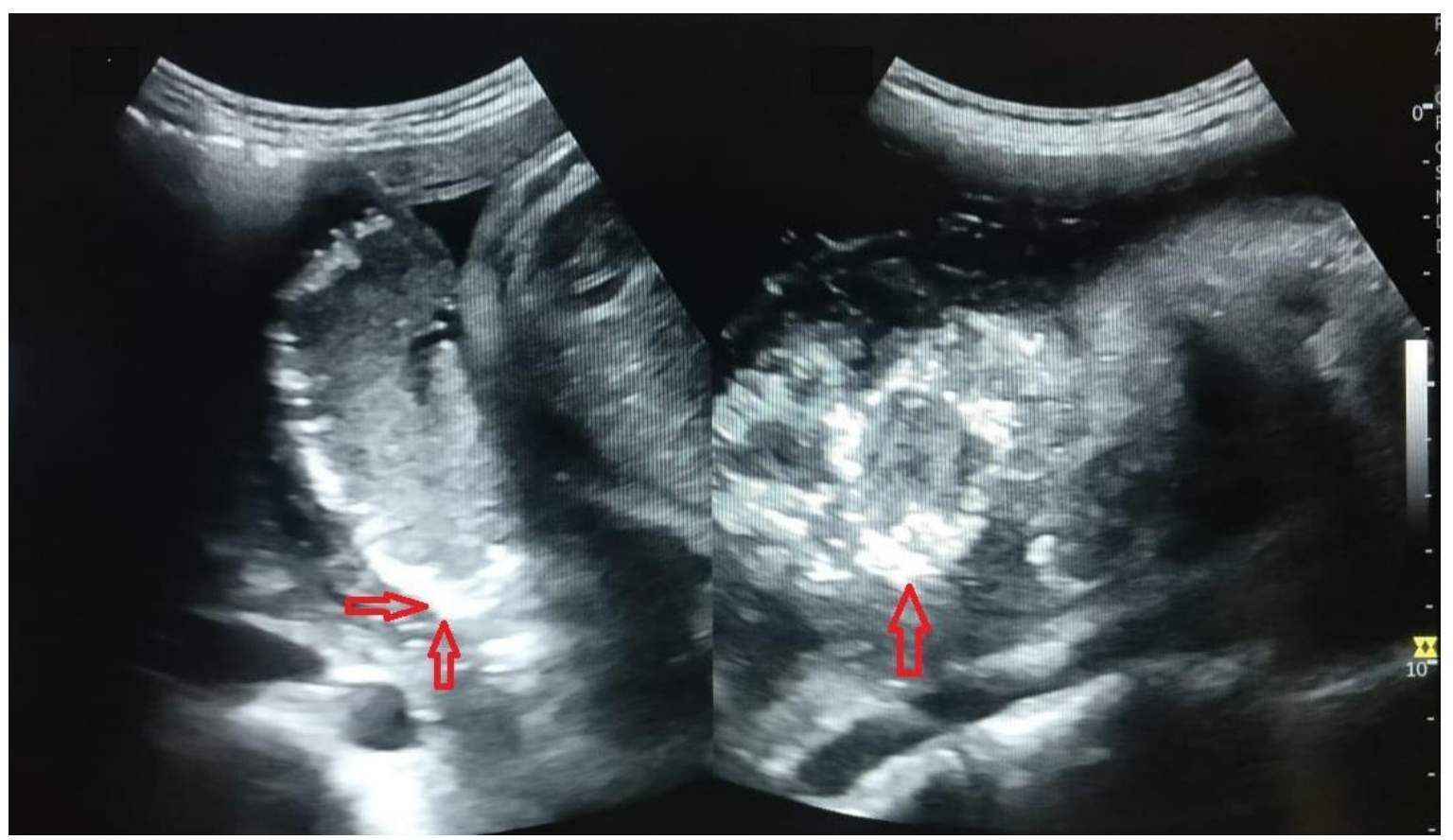

(B)

Figure 2. (A) Image showing placental calcification and lobulation (grade 3 placenta) in a case of 26-year-old primigravida at a gestational age of 33 weeks and 6 days. Red arrows show the placental calcification and blue arrows show lobulations. (B) Image showing grade 3 placental calcification in a 31-year-old primigravida at a gestational age of 35 weeks and 1 day. Red arrows show the placental calcification.

\subsection{Statistical Analysis}

The data were tabulated and expressed as mean \pm SD or frequency and percentage for continuous and categorical variables, respectively. Chi-square or Fisher Exact test was used to determine the association between two categorical variables. The student's $t$-test was performed to test the significance of the difference between the two groups. All statistical calculations were performed using the SPSS software version 21 , and a $p$-value $\leq$ of 0.05 was considered statistically significant.

\section{Results}

A total of 494 pregnant women were included in our analysis. Out of these, 354 (71.7\%) did not show any evidence of PPC (group A) and 140 (28.3\%) did show evidence of PPC (group B). The two groups were similar in context with the baseline characteristics (Table 1). The maternal and perinatal outcomes of the two groups are compared in Tables 2 and 3 , respectively. The incidence of preeclampsia (16.7\% versus $28.6 \%$; $p$-value- 0.002$)$, at least one abnormal Doppler index (20.9\% versus $35.7 \%$; $p$-value- 0.001$)$, obstetrics cholestasis (6.8\% versus $14.3 \%$; $p$-value- 0.008$)$, placental abruption $(8.1 \%$ versus $17.1 \%$; $p$-value- 0.004$)$, and FGR (11\% versus $21.4 \%$; $p$-value-0.002) were significantly higher in the group having PPC. These parameters bear a relative risk (95\% CI) of 1.71 (1.2074 to 2.4339), 1.70 (1.2647 to 2.3080), 2.1 (1.2033 to 3.6898), 2.09 (1.2639 to 3.4647), and 1.94 (1.2604 to 3.0017), respectively for preeclampsia, at least one abnormal Doppler index, obstetrics cholestasis, placental abruption, and FGR (Table 2 and Figure S1). At the same time, we did not find any statistical difference between the incidence of GDM (gestational Diabetes Mellitus), PPROM (preterm premature rupture of membranes), maternal anemia, hemoglobinopathies, postpartum hemorrhage, and mode of delivery between the two groups. 
Table 1. Characteristics of women in the two study groups.

\begin{tabular}{|c|c|c|c|}
\hline Characteristics & $\begin{array}{l}\text { Group A (Those without } \\
\text { Premature Placental } \\
\text { Calcification) } \\
n=354\end{array}$ & $\begin{array}{l}\text { Group B (Those with } \\
\text { Premature Placental } \\
\text { Calcification) } \\
\text { n }=140\end{array}$ & $p$-Value \\
\hline Maternal age (y) & $26.79 \pm 2.05$ & $26.36 \pm 2.34$ & $>0.05$ \\
\hline $\begin{array}{l}\text { Body mass index } \\
\qquad\left(\mathrm{kg} / \mathrm{m}^{2}\right)\end{array}$ & $23.9 \pm 2.05$ & $24.3 \pm 1.95$ & $>0.05$ \\
\hline \multicolumn{4}{|c|}{ Socio-Economic status } \\
\hline Lower & $82(23.1 \%)$ & $36(25.7 \%)$ & \multirow{3}{*}{$>0.05$} \\
\hline Lower middle & $192(54.2 \%)$ & $71(50.7 \%)$ & \\
\hline Upper middle & $80(22.7 \%)$ & $24(23.6 \%)$ & \\
\hline \multicolumn{4}{|c|}{ Parity } \\
\hline Primigravida & $148(41.8 \%)$ & $48(34.2 \%)$ & \multirow{2}{*}{$>0.05$} \\
\hline Multigravida & $206(58.2 \%)$ & $92(65.8 \%)$ & \\
\hline
\end{tabular}

Table 2. The maternal outcome for the selected cohort of pregnant women.

\begin{tabular}{|c|c|c|c|c|c|}
\hline & $\begin{array}{c}\text { Total } \\
\mathrm{n}=494\end{array}$ & $\begin{array}{c}\text { Group A (Those without } \\
\text { Premature Placental } \\
\text { Calcification) } \\
\mathbf{n}=354\end{array}$ & $\begin{array}{c}\text { Group B (Those with } \\
\text { Premature Placental } \\
\text { Calcification) } \\
\mathbf{n}=140\end{array}$ & $p$-Value & $\begin{array}{l}\text { Relative Risk } \\
\quad(95 \% \mathrm{CI})\end{array}$ \\
\hline Pre-eclampsia & $99(20.0)$ & $59(16.7)$ & $40(28.6)$ & 0.002 & 1.71 (1.20 to 2.43$)$ \\
\hline GDM & $58(11.7)$ & $40(11.3)$ & $18(12.8)$ & 0.626 & 1.13 (0.67 to 1.91$)$ \\
\hline $\begin{array}{l}\text { At least one abnormal } \\
\text { Doppler index (uterine or } \\
\text { umbilical or fetal middle } \\
\text { cerebral arterial index)* }\end{array}$ & $124(25.1)$ & $74(20.9)$ & $50(35.7)$ & 0.001 & 1.70 (1.26 to 2.30$)$ \\
\hline PPROM & $147(29.7)$ & $97(27.4)$ & $50(35.7)$ & 0.063 & 1.30 (0.98 to 1.72$)$ \\
\hline ANEMIA & $25(5.1)$ & $15(4.2)$ & $10(7.1)$ & 0.1871 & $1.68(0.77$ to 3.66$)$ \\
\hline Obstetrics cholestasis & $44(8.9)$ & $24(6.8)$ & $20(14.3)$ & 0.009 & 2.1 (1.20 to 3.68$)$ \\
\hline FGR & $69(14.0)$ & $39(11.0)$ & $30(21.4)$ & 0.002 & 1.94 (1.26 to 3.00$)$ \\
\hline Hemoglobinopathy & $15(03.0)$ & $10(2.8)$ & $5(3.6)$ & 0.663 & 1.26 (0.44 to 3.63$)$ \\
\hline Placental abruption & $53(9.3)$ & $29(8.1)$ & $24(17.1)$ & 0.004 & 2.09 (1.26 to 3.46$)$ \\
\hline $\mathrm{PPH}$ & $45(9.1)$ & $31(8.75)$ & $14(10)$ & 0.664 & 1.14 (0.62 to 2.08$)$ \\
\hline Maternal transfer to ICU & $78(15.7)$ & $49(13.8)$ & $29(20.7)$ & 0.057 & 1.49 (0.98 to 2.26$)$ \\
\hline
\end{tabular}

* Doppler indices measured were UMB PI $>95$ th, MCA PI $\leq 5$ th, CPR $\leq 5$ th, Mean uterine PI $>$ 95th and unilateral or bilateral notch in uterine artery. GDM: Gestational Diabetes Mellitus; PPROM: preterm premature rupture of membranes; PPH: post-partum hemorrhage; FGR: Fetal growth restricted pregnancies; Umb PI, Umbilical pulsatility index; MCA, Middle cerebral artery; CPR, Cerebroplacental ratio.

As far as neonatal outcome is concerned, we found a significantly increased incidence of Low APGAR (6.8\% versus 14.3\%; $p$-value-0.004), NICU (Neonatal Intensive Care Unit) admission $(4.2 \%$ versus $7.1 \%$; $p$-value- 0.026$)$, abnormal cardiotocography ( $11 \%$ versus $18.5 \%$; $p$-value- 0.024$)$, meconium-stained liquor ( $8.7 \%$ versus $17.8 \%$; $p$-value- 0.004$)$, and low birth weight (LBW) babies (24.01\% versus $32.8 \%$; $p$-value- 0.04$)$ in those with PPC. These bear a relative risk $(95 \% \mathrm{CI}$ ) of 2.10 (1.2639 to 3.4647), 2.10 (1.0927 to 4.0634), 1.68 (1.0684 to 2.6597$), 2.03$ (1.2503 to 3.3258), and 1.36 (1.0130 to 1.8484 ), respectively. However, the difference was not significant between the two groups as far as preterm birth or neonatal death is concerned (Table 3 and Figure S2).

Comparison of Doppler parameters between the two groups is shown in Table 4 . As one can notice, parameters such as UMB PI $\geq 95$ th, MCA PI $\leq 5$ th, CPR $\leq 5$ th, and AREDF had significantly worse values in the group of pregnant women with PPC. The indications of LSCS are shown in Table 5. 
Table 3. Perinatal outcome for the selected cohort of pregnant women.

\begin{tabular}{|c|c|c|c|c|c|}
\hline & Total $(n=494)$ & $\begin{array}{l}\text { Group A (Those without } \\
\text { Prematureplacental } \\
\text { Calcification) } \\
n=354\end{array}$ & $\begin{array}{l}\text { Group B (Those with } \\
\text { Premature Placental } \\
\text { Calcification) } \\
n=140\end{array}$ & $p$-Value & $\begin{array}{l}\text { Relative Risk } \\
\text { (95\% CI) }\end{array}$ \\
\hline Preterm birth & $70(14.2)$ & 45 (12.7) & $25(17.9)$ & 0.139 & 1.40 (0.89 to 2.19$)$ \\
\hline Low APGAR & $53(08.9)$ & $29(6.8)$ & $24(14.3)$ & 0.004 & 2.10 (1.26 to 3.46$)$ \\
\hline NICU Admission & $33(05.1)$ & $18(4.2)$ & $15(7.1)$ & 0.026 & $2.10(1.09$ to 4.06$)$ \\
\hline Abnormal CTG & $65(13.15)$ & $39(11.0)$ & $26(18.5)$ & 0.024 & 1.68 (1.06 to 2.65$)$ \\
\hline Meconium-stained liquor & $56(11.3)$ & $31(8.7)$ & $25(17.8)$ & 0.004 & 2.03 (1.25 to 3.32$)$ \\
\hline LBW & $124(25.1)$ & $85(24.01)$ & $46(32.8)$ & 0.040 & 1.36 (1.01 to 1.84$)$ \\
\hline Birth weigt (g) & $2714.25+496.62$ & $2575.04+606.75$ & 0.008 & & \\
\hline Gestation at delivery & $38 w k 3 d+1 w k 5 d$ & $38 w k 0 d+1 w k 6 d$ & 0.056 & & \\
\hline Delivery Mode (LSCS) & $172(34.8)$ & $118(33.3)$ & $54(38.5)$ & 0.263 & 1.11 (0.89 to 1.49$)$ \\
\hline Neonatal death & $15(03.0)$ & $10(2.8)$ & $5(3.6)$ & 0.663 & $1.26(0.44$ to 3.63$)$ \\
\hline
\end{tabular}

NICU: neonatal intensive care unit; LBW: low birth weight babies; CTG: Cardiotocography; LSCS: lower segment caesarean section.

Table 4. Comparison of Doppler abnormalities between the two groups.

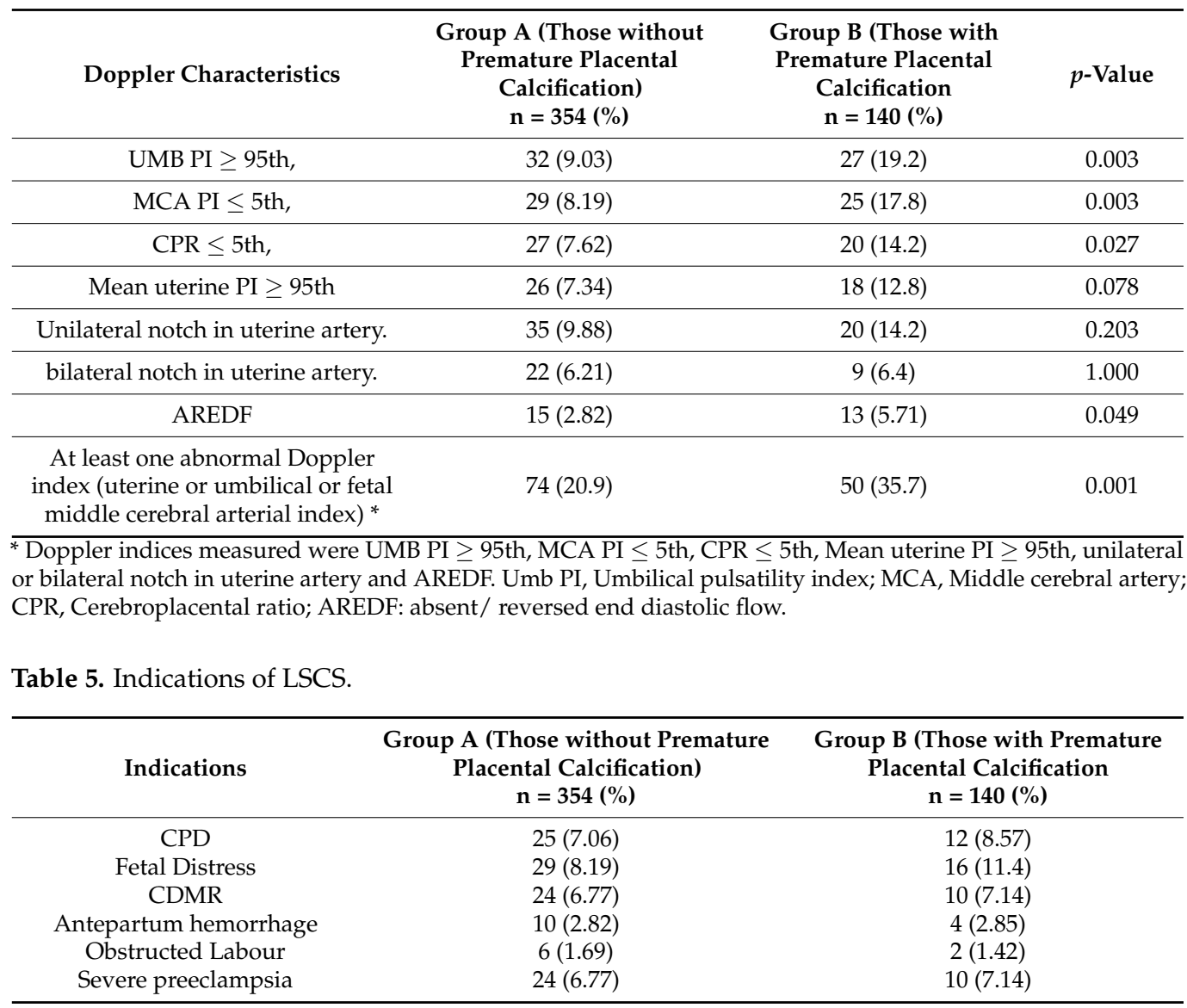

The performance of PPC is shown in Table 6. This shows that for most of the adverse perinatal outcomes, the negative predictive value and specificity of PPC is very good. The negative predictive value of PPC is highest for NICU admission (94.9\%), followed by Low APGAR (91.8\%), placental abruption (91.8\%), Meconium-stained liquor (91.2\%), FGR pregnancies $(89 \%)$, and abnormal Doppler parameters $(79.1 \%)$. Similarly, the specificity was found to be highest for abnormal Doppler parameters $(75.7 \%)$ followed by preeclampsia $(74.7 \%)$, FGR pregnancies and LBW babies (74.1\%), Low APGAR (73.7\%), placental 
abruption (73.7\%), Meconium-stained liquor (73.7\%), abnormal CTG (73.4\%), and NICU admission $(72.9 \%)$.

Table 6. Performance of premature placental calcification.

\begin{tabular}{ccccc}
\hline & $\begin{array}{c}\text { Sensitivity } \\
\mathbf{( \% )}\end{array}$ & $\begin{array}{c}\text { Specificity } \\
\mathbf{( \% )}\end{array}$ & $\begin{array}{c}\text { Positive } \\
\text { Predictive Value } \\
\mathbf{( \% )}\end{array}$ & $\begin{array}{c}\text { Negative } \\
\text { Predictive Value } \\
\mathbf{( \% )}\end{array}$ \\
\hline preeclampsia & 40.4 & 74.7 & 28.6 & 83.3 \\
\hline FGR & 43.5 & 74.1 & 21.4 & 89 \\
\hline $\begin{array}{c}\text { PLACENTAL } \\
\text { ABRUPTION }\end{array}$ & 45.3 & 73.7 & 17.1 & 91.5 \\
\hline Low APGAR & 45.3 & 73.7 & 17.1 & 91.5 \\
\hline NICU admission & 45.5 & 72.9 & 10.7 & 94.9 \\
\hline Abnormal CTG & 40 & 73.4 & 18.6 & 89 \\
\hline Meconium-stained liquor & 44.6 & 73.7 & 17.9 & 91.7 \\
\hline LBW & 35.1 & 74.1 & 32.9 & 76 \\
\hline Abnormal Doppler & 40.3 & 75.7 & 35.7 & 79.1 \\
\hline
\end{tabular}

\section{Discussion}

In our study, premature placental calcification was associated with adverse maternal and neonatal outcomes, such as preeclampsia, at least one abnormal Doppler index, obstetrics cholestasis, placental abruption, FGR, maternal ICU admission, low birth weight babies, and low neonatal APGAR scores.

PPC can cause gradual narrowing of placental vessels due to the deposition of calcium and fibrin, leading to decreased uteroplacental blood flow. This way, it can cause an adverse feto-maternal outcome. There are two possible explanations for our findings [9]. In fact, as evidence for this hypothesis, widespread basement membrane mineralization [10], focal calcification, and acute atherosclerosis in the placental vessels [11] were found on pathologic examination of the placentas in fetal Bartter syndrome. A similar case was reported where massive calcification and thrombi, including the chorionic and umbilical vessels, were the cause of severe fetal growth restriction [12].

Another hypothesis for PPC leading to poor uteroplacental blood flow and adverse feto-maternal outcomes could be via an unknown root cause that had remained uninvestigated. However, there is no direct research supporting this theoretical view. We theorize that myometrial contraction causing tissue separation in the interface contributed by hormones could lead to early detachment. The process could be mediated via some unknown pathway in the placenta involved with preterm calcification. These events are pretty similar to the separation of deciduas spongiosa and the formation of a retroplacental hematoma at term [13].

According to our study, in high-risk pregnant women, premature placental calcification is a pathological event that may have a different mechanism from that of placental calcification found at term. It was observed that the disorders of calcium pumps located at the placental basement membrane [14] could play a significant role in excessive calcium deposition in the placenta. This can lead to marked calcification of the placental basement membrane. There is also evidence that nanobacteria play a central role in early pathologic calcification, albeit in limited cases $[15,16]$. Although a detailed analysis of the calcification cascade is out of context for this discussion, future research should explore such relationships. Similar to our study, some other authors have also found preterm placental calcification to be associated with a greater incidence of fetal growth restriction [6,7,17-19], low birth weight $[6,7,18-21]$, low APGAR scores [18], and pregnancy-induced hypertension $[6,17,19,22]$. On the other hand, some other authors did not find any association of preterm placental calcification with fetal growth restriction [23,24], low birth weight [25], and low APGAR scores [25]. As suggested by the Euronatal audit study, there might be 
a reduction in the incidence of stillbirth rates with improvements in the detection and management of growth-restricted fetuses [26]. In their study, Mirza and his group found a significant association of PPC with low-birth-weight babies and perinatal death [27]. In line with our study, other recent studies also found PPC is associated more commonly with abnormal uterine and Umbilical Artery Doppler indices [8,28].

According to our study, the negative predictive value and specificity of PPC for predicting poor perinatal outcome is very high. This indicates that absence of PPC in any pregnant women can be extremely useful in low resource settings to identify a subcategory of low-risk pregnant women who may not need any future referral to specialized centers. Thus, these pregnancies can be safely managed in these particular places. On the other hand, the presence of PPC may warrant clinicians to perform Doppler ultrasound evaluation of placenta and fetus in such pregnancies.

\section{Strengths and Limitations}

The strengths of this study lies in the fact that it is a well-designed prospective cohort study. However, certain limitations should be considered while analyzing the results of the study. First, our study was performed in a tertiary care hospital. Applying the conclusions to low-resource settings is not necessarily valid because of questionable external validity. Second, the placental histology was not performed to confirm the placental calcification found on ultrasonography. However, to be specific, the parameter we intended to evaluate initially was ultrasonographically diagnosed PPC or premature grade 3 placental maturity. Thus, there was no need to do a placental histology to corroborate the ultrasound finding. Third, the performance of PPC could have been better characterized in a larger sample size.

\section{Conclusions}

Premature placental calcification should be considered as one of the reasons for underlying placental dysfunction and not as a mere physiological aging process. It is associated with increased maternal complications as well as increased adverse neonatal outcomes. Hence, these women should be carefully investigated with antepartum surveillance for fetal wellbeing and monitored for maternal complications. We suggest that clinicians be aware of documenting placental grading while performing ultrasonography during 28 to 36 weeks. This is especially true for low resource settings, where the absence of PPC can define a subcategory of low-risk pregnant populations, which probably need no referral to a specialized center and can be managed in these settings. However, future wellcontrolled prospective studies with large sample sizes are required to better characterize the performance of PPC as a predictor of poor feto-maternal outcome.

Supplementary Materials: The following are available online at https:/ /www.mdpi.com/article/10 $.3390 /$ clinpract11040099/s1, Figure S1: The maternal outcome for the selected cohort of pregnant women, Figure S2: Perinatal outcome for the selected cohort of pregnant women.

Author Contributions: Conceptualization, S.D.; Data curation, S.D., B.D., M.R., P.J. and S.K.R.; Formal analysis, S.D., B.D. and S.R.P.; Investigation, S.D.; Supervision, S.D., S.R.P., P.J. and S.K.R.; Validation, A.M.; Visualization, S.R.P. and M.R.; Writing-original draft, S.R.P.; Writing—review and editing, S.D., P.J., A.M. and S.K.R. All authors have read and agreed to the published version of the manuscript.

Funding: The study received no external funding.

Institutional Review Board Statement: The study was conducted according to the guidelines of the Declaration of Helsinki, and approved by the Institutional Ethics Committee with EC registration number KIMS/KIIT/IEC/38/2017 dated 13.06.2017 of Kalinga Institute of Medical Science, Bhubaneswar.

Informed Consent Statement: Informed consents were obtained from all subjects involved in the study.

Acknowledgments: We thank Swetaparna Khuntia for his valuable contribution in guiding us to complete this project and Subhadra Priyadarshini from the Research and development cell, KIMS, 
for her timely and sincere help at crucial moments during this project. We also thank Saswat Dash in revising and editing the manuscript.

Conflicts of Interest: The authors declare that there are no conflict of interest.

\section{References}

1. Harris, R.D.; Alexander, R.D. Ultrasound of the placenta and umbilical cord. In Ultrasonography in Obstetrics and Gynaecology; Callen, P.W., Ed.; W.B. Saunders: Philadelphia, PA, USA, 2000; pp. 602-604.

2. Nolan, R.L. The placenta, membranes, umbilical cord, and amniotic fluid. In A Practical Guide to Ultrasound in Obstetrics and Gynaecology; Sauerbrei, E.E., Nguyen, K.T., Nolan, R.L., Eds.; LippincottRaven: Philadelphia, PA, USA, 1998 ; pp. $438-439$.

3. Winsberg, F. Echographic changes with placental ageing. J. Clin. Ultrasound 1973, 1, 52-55. [CrossRef]

4. Grannum, P.A.; Berkowitz, R.L.; Hobbins, J.C. The ultrasonic changes in the maturing placenta and their relation to fetal pulmonic maturity. Am. J. Obstet. Gynecol. 1979, 133, 915-922. [CrossRef]

5. Spirt, B.A.; Gorden, L.P. Sonography of the placenta. In Sonography in Obstetrics and Gynecology: Principles and Practice; Fleischer, A.C., Manning, F.A., Jeanty, P., Romero, R., Eds.; McGraw-Hill: New York, NY, USA, 2001; pp. 195-197.

6. McKenna, D.; Tharmaratnam, S.; Mahsud, S.; Dornan, J. Ultrasonic evidence of placental calcification at 36 weeks' gestation: Maternal and fetal outcomes. Acta Obstet. Gynecol. Scand. 2005, 84, 7-10. [CrossRef] [PubMed]

7. Chitlange, S.; Hazari, K.; Joshi, J.; Shah, R.; Mehta, A. Ultrasonographically observed preterm grade III placenta and perinatal outcome. Int. J. Gynecol. Obstet. 1990, 31, 325-328. [CrossRef]

8. Jamal, A.; Moshfeghi, M.; Moshfeghi, S.; Mohammadi, N.; Zarean, E.; Jahangiri, N. Is preterm placental calcification related to adverse maternal and foetal outcome? J. Obstet. Gynaecol. 2017, 37, 605-609. [CrossRef] [PubMed]

9. Emmrich, P. Pathology of the placenta. X. Syncytial proliferation, calcification, cysts, pigments and metabolic disorders. Zent. Pathol. 1992, 138, 77-84. (In German)

10. Ernst, L.; Parkash, V. Placental Pathology in Fetal Bartter Syndrome. Pediatr. Dev. Pathol. 2002, 5, 76-79. [CrossRef] [PubMed]

11. Dane, B.; Dane, C.; Aksoy, F.; Cetin, A.; Yayla, M. Antenatal Bartter syndrome: Analysis of two cases with placental findings. Fetal Pediatr. Pathol. 2010, 29, 121-126. [CrossRef]

12. Klaritsch, P.; Haeusler, M.; Karpf, E.; Schlembach, D.; Lang, U. Spontaneous intrauterine umbilical artery thrombosis leading to severe fetal growth restriction. Placenta 2008, 29, 374-377. [CrossRef]

13. Cunningham, F.G.; Leveno, K.J.; Bloom, S.L.; Hauth, J.C.; Rouse, D.J.; Spong, C.Y. Parturition. In Williams Obstetrics; Cunningham, F.G., Ed.; McGraw-Hill: New York, NY, USA, 2010; pp. 146-147.

14. Kasznica, J.M.; Petcu, E.B. Placenta calcium pump: Clinical-based evidence. Pediatr. Pathol. Mol. Med. 2003, 22, 223-227. [CrossRef]

15. Agababov, R.M.; Abashina, T.N.; Suzina, N.E.; Vainshtein, M.B.; Schwartsburd, P.M. Link between the early calcium deposition in placenta and nanobacterial-like infection. J. Biosci. 2007, 32, 1163-1168. [CrossRef] [PubMed]

16. Pasquinelli, G.; Papadopulos, F.; Nigro, M. Nanobacteria and psammoma bodies: Ultrastructural observations in a case of pathological placental calcification. Ultrastruct. Pathol. 2010, 34, 344-350. [CrossRef]

17. Hills, D.; Irwin, G.; Tuck, S.; Baim, R. Distribution of placental grade in high-risk gravidas. Am. J. Roentgenol. 1984, 143, 1011-1013. [CrossRef] [PubMed]

18. Patterson, R.M.; Hayashi, R.H.; Cavazos, D. Ultrasonographically observed early placental maturation and perinatal outcome. Am. J. Obstet. Gynecol. 1983, 147, 773-777. [CrossRef]

19. Valenzuela, A.B.; Mendez, A.G. Premature aging of the placenta. Ultrasonic diagnosis. Ginecol. Obs. Mex. 1995, 63, $287-292$.

20. Proud, J.; Grant, A.M. Third trimester placental grading by ultrasonography as a test of fetal wellbeing. BMJ 1987, $294,1641-1644$. [CrossRef] [PubMed]

21. Zhang, L.-Y.; Yu, Y.-H.; Hu, M.-L. Association between ultrasonographic signs of placental premature aging and pregnancy outcome. Di 1 Jun Yi Da Xue Xue Bao = Acad. J. First Med. Coll. PLA 2005, 25, 318-320. (In Chinese)

22. Kazzi, G.M.; Gross, T.L.; Rosen, M.G.; Jaatoul-Kazzi, N.Y. The relationship of placental grade, fetal lung maturity, and neonatal outcome in normal and complicated pregnancies. Am. J. Obstet. Gynecol. 1984, 148, 54-58. [CrossRef]

23. Miller JMJr Brown, H.L.; Kissling, G.A.; Gabert, H.A. The relationship of placental grade to fetal size and growth at term. Am. J. Perinatol. 1988, 5, 19-21. [CrossRef]

24. Vosmar, M.B.J.G.; Jongsma, H.W.; Dongen, P.W.J. The value of ultrasonic placental grading: No correlation with intra-uterine growth retardation or with maternal smoking. J. Périnat. Med. 1989, 17, 137-143. [CrossRef]

25. Zhang, L.Y.; Yu, Y.H.; Hu, M.L. The relationship between placental aging, Doppler indices of umbilical artery and fetal prognosis. J. Pract. Obstet. Gynecol. 2005, 5, 315-318.

26. Richardus, J.H.; Graafmans, W.C.; Bruin, K.M.V.D.P.-D.; Amelink-Verburg, M.P.; Verloove-Vanhorick, S.P.; MacKenbach, J.P. An European concerted action investigating the validity of perinatal mortality as an outcome indicator for the quality of antenatal and perinatal care. J. Périnat. Med. 1997, 25, 313-324. [PubMed]

27. Mirza, F.G.; Ghulmiyyah, L.M.; Tamim, H.M.; Makki, M.; Jeha, D.; Nassar, A.H. To Ignore or Not To Ignore Placental Calcifications on Prenatal Ultrasound: A Systematic Review and Meta-analysis. J. Matern. Neonatal Med. 2017, 31, 1-21. [CrossRef]

28. Agarwal, R.; Tiwari, A.; Wadhwa, N.; Radhakrishnan, G.; Bhatt, S.; Batra, P. Abnormal umbilical artery Doppler velocimetry and placental histopathological correlation in fetal growth restriction. S. Afr. J. Obstet. Gynaecol. 2017, 23, 12. [CrossRef] 